\title{
Does Internet Promote Green Growth? An Empirical Test from China
}

\author{
Deshan $\mathrm{Li}^{1 *}$, Yanfen $\mathrm{Zhao}^{2}$ \\ ${ }^{1}$ College of Economics, Shanxi University of Finance and Economics, Taiyuan, China \\ ${ }^{2}$ College of Resources and Environment, Shanxi University of Finance and Economics, Taiyuan, China
}

Received: 6 November 2020

Accepted: 8 March 2021

\begin{abstract}
We constructed an internet development index and used inter-provincial panel data from China between 2006 and 2016 to empirically test the impact and the mechanism by which internet influenced green productivity. Internet strongly promoted green productivity growth in China, and its influence showed clear regional heterogeneity, with positive effects in the eastern and central regions but no effect in the western region. Internet not only promoted green productivity directly, but also had an indirect positive effect on green productivity by accelerating technological innovation and industrial structure upgrades. Nonetheless, its direct effects far exceeded its indirect effects. More importantly, we found that the positive effect of internet on China's green productivity showed significant non-linear characteristics. When the development level of internet crossed a critical threshold, its influence was significantly enhanced. At the same time, $R \& D$ investment and industrial structure upgrading can further strengthen the network effect of internet. These findings provide important theoretical guidance for the application of internet and associated strategies to promote green economic growth in China.
\end{abstract}

Keywords: internet, green productivity, technological innovation

\section{Introduction}

Although China has made remarkable strides in economic growth, these achievements have required substantial resources and resulted in a large amount of greenhouse gas emissions and serious air pollution [1-4]. The cost associated with ecological damage and environmental pollution in China is reported to have reached 2.63 trillion yuan, accounting for $3 \%$ of the GDP [5]. Therefore, green development has become an inevitable choice during this period of

*e-mail: 20171074@sxufe.edu.cn economic transformation. Green growth is an efficient, environmentally friendly, and sustainable means of economic development that can produce a win-win situation for both the social economy and the ecological environment [6, 7]. In recent years, China has gradually given up the traditional model of high growth and high pollution, instead advancing the concept of green development, which has been promoted as a national strategy. Determining how green development can be realized is therefore an important challenge for the Chinese government at all levels. To achieve green development, we must find new ways to meet the reality of China's ongoing development. Based on the view that information technology can improve the efficiency of resource and energy utilization and reduce 
transaction costs, some scholars have pointed out that the information industry is increasingly important to the development of a country's economy, especially the green economy $[8,9]$.

With rapid developments in information technology, internet is increasingly widely used in China's economic society. According to a report from the China Internet Network Information Center, the number of internet users in China was 829 million and the internet penetration rates reached $59.6 \%$ in 2018 , making it one of the most developed internet systems in the world [10]. The government has put forward a strategy of deep integration of internet with the real economy in order to promote technological innovation and upgrades in industrial infrastructure, thereby providing an important means for green development in China. A question worthy of consideration is whether the rapid development of internet will contribute to China's regional green development. If the answer is yes, then what is the internal mechanism by which internet promotes green growth? Is there a network effect of internet development on green growth? Evaluating the role of internet development in China's green growth has great theoretical and practical significance for the government's formulation and implementation of relevant policies.

Many scholars have investigated the impact of environmental regulation [11], technological innovation [12], and foreign direct investment on green growth [13], and have drawn many valuable conclusions. With the rise of internet economy and the digital economy, some have also discussed the relationship between internet and economic growth [14, 15]. However, few studies have directly addressed the inherent relationship between internet development and green growth. Therefore, the present research makes three main contributions to this subject. First, this study creatively integrates the internet and green productivity into a framework and empirically tests the impact of internet on green growth at the regional level, which provides a new perspective on how to promote green growth. Second, we designed a multi-dimensional indicator system and constructed an internet development index based on previous research in order to objectively capture the internet development level. We also employed the Global Malmquist Luenberger (GML) index to measure the level of regional green growth rather than traditional productivity. Finally, we analyzed the mechanism by which internet influences regional green development and explored whether there was a network effect between internet and green development. We theoretically analyzed and empirically tested the internal mechanism by which internet development promotes green growth, thereby compensating for a lack of mechanistic tests in related research. The results provide a reference for the green transformation of China's economy.

The remainder of this article is arranged as follows: Section 2 is a review of related literature; Section
3 presents the research framework and literature hypothesis; Section 4 outlines research methods and data collection; and Section 5 presents and discusses the findings. The final section summarizes the research conclusions and provides policy recommendations.

\section{Literature Review}

Previous work has shown that internet plays a useful role in economic or productivity growth, as it can accelerate the spread of information, stimulate technological innovation, strengthen market competition, foster business, and so on [16]. Internet permits the exchange of information without time and space constraints, and companies can therefore use it to communicate more quickly and easily. Internet can reduce transaction costs, thereby lowering production costs and improving productivity [17].

Some studies have found that internet can significantly promote economic growth. Choi and Hoon Yi [18] used data from more than 200 economies between 1990 and 2000 to demonstrate that internet has a positive and significant impact on economic growth. They reported that a $1 \%$ increase in the share of internet users led to a growth rate of $0.05 \%$. Czernich and Falck et al. [19] used data from OECD countries between 1996 and 2007 to show that for every $10 \%$ increase in internet penetration, the annual growth rate of per capita GDP increased by $0.9-1.5 \%$. Chu [16] used panel data from 201 countries between 1988 and 2010 to demonstrate that a $10 \%$ increase in internet penetration increased the per capita real GDP by $0.57-0.63 \%$. However, Maurseth [20] reexamined the Choi and Hoon Yi [18] study and found that internet had a significant negative impact on economic growth when the data were extended to 2015 . In response to this contradictory conclusion, $\mathrm{Vu}$ [21] proposed a modified model that avoided the problems of endogeneity and omitted variable bias, and found that internet penetration had a significant positive effect on economic growth. This research also showed that there were significant network effects and that the growth effect of internet penetration increased with the expansion of the network scale of internet.

Internet has a significant impact on technological innovation. As one of the information technologies, internet accelerates the spread or spillover of knowledge and promotes technological innovation [17]. Internet platforms enable the formation of innovative social networks, promote the production and exchange of innovative thinking, and accelerate the speed of innovation [22]. The empirical research of Glavas and Mathews [23] suggests that the accumulation of corporate internet capabilities has had a positive impact on the innovation and initiative of enterprises. Based on data from 50,013 enterprises in developing and emerging countries, Paunov and Rollo [24] showed that enterprises with high efficiency and strong absorptive capacity were more likely to obtain innovation benefits 
from internet. Han, Song and $\mathrm{Li}$ [25] found that internet not only directly promoted regional innovation efficiency, but also indirectly had a positive impact on regional innovation efficiency by accelerating human capital accumulation, financial development, and industrial upgrades.

Internet has an important impact on key industries or sectors. With regard to internet and international trade relations, Vemuri and Siddiqi [26] used panel data from 64 countries between 1985 and 2005 to demonstrate a positive relationship between internet and trade. Clarke and Wallsten [27] used instrumental variables to overcome endogeneity problems and predicted that increased internet penetration in developing countries would stimulate exports to developed countries. Other studies have shown that internet has greater effects on trade in non-high-income countries than in high-income countries $[15,27]$. Internet has also improved the labor market. Internet use helps to achieve better job matching [28], enhances job satisfaction [29], and facilitates reemployment of the unemployed [30]. Stevenson [31] found that internet provides more symmetrical information for the labor market and more opportunities for reemployment and job hopping, thereby increasing the mobility of the labor market.

Internet use affects not only the economy but also resources and environmental performance. Although internet has positive economic effects, studies on its consequences for the environment have been inconclusive. Some findings support a positive role for Internet use in reducing emissions [32-35]. Ozcan and Apergis [36] employed panel data from twenty emerging economies to show that internet use reduced air pollution levels. Danish [9] found that information and communication technology reduced carbon dioxide emissions in the Belt and Road countries. Other studies have suggested that internet has an adverse impact on the environment. For example, Salahuddin et al. [37] found that internet use would stimulate carbon dioxide emissions over the long term. Lee and Brahmasrene [38] confirmed that internet use contributed positively to economic growth and $\mathrm{CO}_{2}$ emissions in Southeast Asian countries. In addition, studies have found that there is a U-curve relationship between the use of information and communication technology and environmental quality [39, 40]. This means that the use of internet harms the environment in the early stages but improves environmental quality later on.

Through the literature review above, we found that most studies primarily investigated the impact of internet use on economic growth or environmental performance. Few scholars have integrated the economy with the environment to explore the impact of internet use on green growth or green productivity. Therefore, the purpose of the present study was to identify the role of internet development in green productivity. To place constraints associated with economic, resource, and environmental factors into the analysis framework, we first constructed a set of production possibilities with expected and undesired outputs, and then used the GML index to measure green productivity. Next, we comprehensively tested the impact strength and internal mechanisms by which internet development affected green productivity in China, overcoming endogeneity by the instrumental variable method. Finally, we further examined the network effects of internet development on regional green productivity using a threshold regression model.

\section{Research Hypothesis}

\section{Direct Mechanisms by Which Internet Affects Green Productivity}

Internet primarily affects green productivity in three ways. First, internet applications change the production and consumption process by providing virtual products, helping to reduce material consumption and pollution discharge [41]. Second, internet has changed traffic by providing virtual mobile forms and intelligent traffic management, thereby reducing energy consumption [42]. Third, the application of internet to the management of energy supply and demand improves energy utilization efficiency [43, 44]. In addition, internet provides efficient and intelligent production and information platforms for enterprises, improves management and decision-making efficiency, and thereby boosts economic efficiency and competitiveness.

Hypothesis 1. Internet plays a positive role in green productivity growth in China.

\section{Indirect Mechanisms by Which Internet Affects Green Productivity}

Internet affects green productivity indirectly through multiple forms of technological innovation. First, internet communication overcomes spatial and temporal constraints, enabling convenient cooperation and promoting closer coordination of labor among innovators. Second, as internet platforms accelerate the mobility of innovation resources and promote the diffusion and spillover of knowledge, researchers can apply information, technology, and other elements of innovation more broadly, thereby accelerating the speed of innovation [24]. Third, internet enables rapid information transfer, allowing enterprises to meet market demand in a timely and convenient manner, effectively matching supply and demand and improving innovation performance. Finally, use of internet enables enterprises to obtain more environmentally-friendly green production and pollutant treatment technologies, thereby improving resource utilization efficiency and environmental pollutant treatment levels.

Internet indirectly affects green productivity through upgrades to industrial structures. This refers to the process by which industrial structures are transformed from low-level to high-level forms; it results from 
a transformation of economic growth mode caused by technological progress. The application of internet provides a strong impetus for the transformation and upgrade of traditional industries. First, the integration of internet with traditional industries has promoted online, digital, and intelligent manufacturing industries, forcing companies to improve production, management, and circulation methods, thereby improving production efficiency. Second, enterprises can achieve large-scale, personalized, customized production in response to the user's specific needs and promote product innovation by quickly acquiring information on consumer demand using internet and big data technology. Third, by fully utilizing internet for information collection, processing, and management, manufacturing companies can optimize production processes and achieve cleaner production, thereby reducing negative environmental impacts. Finally, the development of internet has given rise to new models, products, and formats, accelerated the formation and emergence of new industries, and driven the development of relevant high-tech industries.

Hypothesis 2. Internet indirectly drives green productivity growth by promoting technological innovation and industrial upgrades.

\section{The Non-Linear impact of Internet on Green Productivity}

Internet has a significant network externality. In other words, the more people use it, the more value those users receive [45]. Roller and Waverman's [46] research confirms that information infrastructure has had a significant network effect on the economic growth of 21 OECD countries . Gruber et al. [47] found that the threshold for a network effect of information and communication infrastructure in EU countries was a $15 \%$ broadband penetration rate. In fact, as internet penetration increases, the transaction costs of information exchange, acquisition, and processing are reduced, bringing obvious benefits for economic growth. This result stimulates internet demand from the application sector, leading to a continuous decline in the marginal cost of information access and increasing gains. With the emergence of this continual positive feedback and response, internet has finally produced network effect characteristics.

Hypothesis 3. The effect of internet on green productivity will be significantly enhanced as the development level of internet improves, showing nonlinear characteristics.

This paper's theoretical hypothesis model, based on the above five assumptions, is presented in Fig. 1.

\section{Methods and Data}

\section{Model Specification}

In this paper, we attempt to place internet and green productivity into an analysis framework, constructing the following basic econometric model:

$$
Y_{i t}=\beta_{0}+\beta_{1} I N T_{i t}+\beta_{c} C V_{i t}+f_{i}+\varepsilon_{i t}
$$

Here, $i$ and $t$ represent region and time, respectively, and $Y$ is green productivity, which is substituted into the GML index. INT refers to the internet development level, $C V$ is the control variable, $f$ represents the unobservable individual fixed effects, and $\varepsilon$ is the random error term.

The above model reflects the direct impact mechanism of internet on regional green productivity. Here, an intermediary variable is introduced to further investigate the potential indirect impact mechanism of internet on green productivity. The intermediary effect model can be expressed as follows:

Direct effect

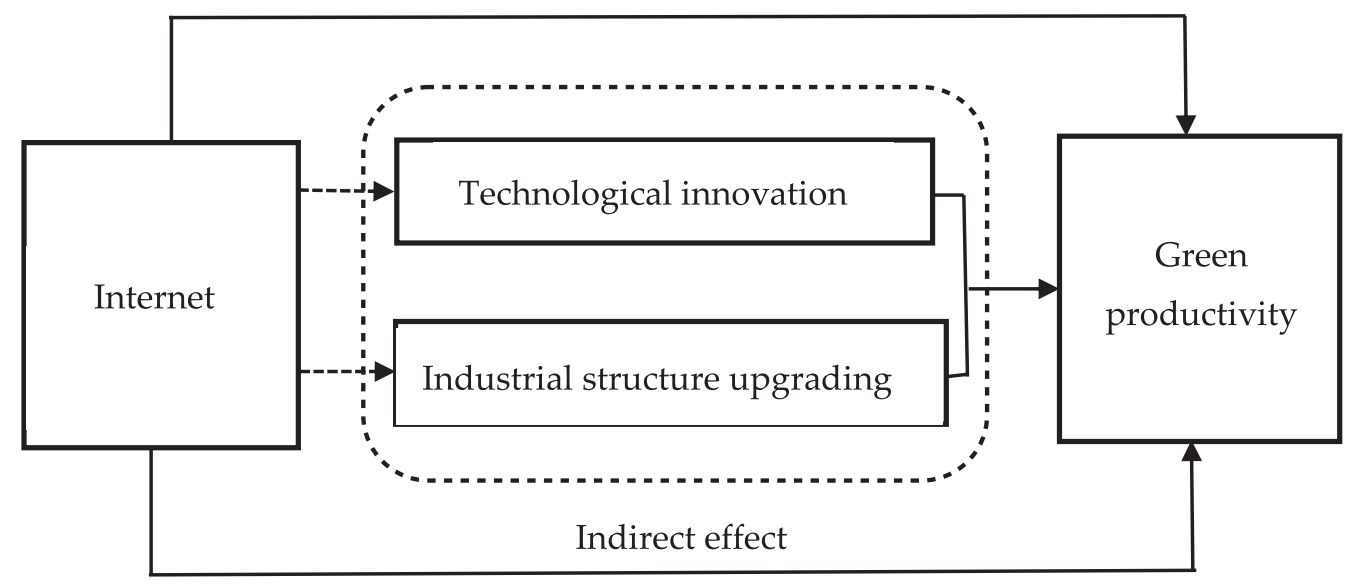

Network effect

Fig. 1 Conceptual model of the theoretical hypothesis. 


$$
\begin{gathered}
M E D_{i t}=\beta_{0}+\beta_{1} I N T_{i t}+\beta_{c} C V_{i t}+f_{i}+\varepsilon_{i t} \\
Y_{i t}=\psi_{0}+\psi_{1} I N T_{i t}+\psi_{2} M E D_{i t}+\psi_{c} C V_{i t}+f_{i}+\varepsilon_{i t}
\end{gathered}
$$

$M E D$ are mediating variables, which includes industrial structure upgrading and technological innovation, and $\psi_{l}$ denotes the direct effect. The indirect effect is expressed as follows:

$$
\text { Indirect effect }=\beta_{1} \cdot \psi_{2}
$$

The total effect is calculated by the following formula:

Total effect $=$ Indirect effect + Direct effect

To test the network effect of internet, we used the panel threshold model proposed by Hansen [48] to investigate the non-linear influence mechanism of internet on green productivity, further developing the model in Equation (6) as follows:

$$
\begin{aligned}
Y_{i t}=\beta_{0}+\beta_{1} I N T_{i t} & \cdot I\left(I N T_{i t} \leq \lambda\right)+\beta_{2} I N T_{i t} \cdot I\left(I N T_{i t}>\lambda\right) \\
+ & \beta_{c} C V_{i t}+f_{i}+\varepsilon_{i t}
\end{aligned}
$$

$I$ (.) is the indicator function: if the condition is satisfied, its value is 1 ; otherwise, its value is $0 . \gamma$ is a specific threshold value, and all other variables have the same meaning as in Equation (1).

\section{Variable Selection}

\section{Green Productivity}

In recent years, many studies have chosen to use the slack-based measurement (SBM) directional distance function to measure green productivity, including such factors as resource consumption and environmental pollution emissions. However, the SBM model measures green productivity from only a static point and cannot reflect dynamic trends. To capture dynamic changes in green productivity, we used the GML index to measure regional green productivity.

Chung et al. [49] constructed a directional distance function that solves the problem of evaluating efficiency, including undesirable output. It is defined as follows:

$$
\overrightarrow{D^{t}}\left(x^{t}, y^{t}, b^{t} ; g\right)=\sup \left\{\beta:\left(y^{t}, b^{t}\right)+\beta, g \in P^{t}\left(x^{t}\right)\right\}
$$

...where $x^{t}$ is the input variable, $g=\left(g_{y}, g_{b}\right)$ represents a directional vector, $y^{t}$ and $g_{y}$ are expected output vectors, and $b^{t}$ and $g_{b}$ are unexpected output vectors. Each decision-making unit (province or city) is assumed to use $N$ inputs, $x=\left(x_{1}, \ldots x_{N}\right) \in R_{+}^{N}$ to produce $\mathrm{m}$ term expected outputs, $y=\left(y_{1}, \ldots y_{M}\right) \in R_{+}^{M}$, and $i$ term unexpected outputs, $b=\left(b_{1}, \ldots b_{I}\right) \in R_{+}^{I}$. The production possibilities $P^{T}(x)$ are then expressed as:

$$
P^{t}(x)=\left\{\left(y^{t}, b^{t}\right), x^{t} \rightarrow\left(y^{t}, b^{t}\right)\right\}, x \in R_{+}^{N}
$$

To enhance the comparability of technological efficiency across decision-making units, Oh [50] defined the global technology set as the union of all current production technology sets, $P^{G}(x)=P^{1}\left(x^{1}\right) \cup$ $P^{2}\left(x^{2}\right) \ldots \cup P^{T}\left(x^{T}\right)$. This permits the calculation of global technological efficiency under a single production frontier, which is comparable among decision-making units and periods.

Referring to Oh's [50] method, this paper constructs the Global Malmquist-Luenberger (GML) index based on the global directional distance function as follows:

$$
G M L_{t}^{t+1}=\frac{1+\overrightarrow{D_{0}}\left(x^{t}, y^{t}, b^{t} ; g\right)}{1+\overrightarrow{D_{0}}\left(x^{t+1}, y^{t+1}, b^{t+1} ; g\right)}
$$

The green productivity growth of Chinese provinces is therefore estimated by the GML index in Equation (9). $\mathrm{A} \mathrm{GML}_{\mathrm{t}}^{\mathrm{t}+1}$ index $>1,<1$ or $=1$ indicates that green productivity increased, decreased, or remained unchanged from $t$ to $t+1$.

Input variables include labor force, capital stock, and energy consumption. Labor force is measured by the total employment population of each province in China. The capital stock is estimated using the perpetual inventory method: the stock of physical capital in a given period is obtained from the current period's physical capital investment plus the previous period's capital stock minus the current period's depreciation. Energy input is expressed as the total energy consumption of each region.

Output variables include expected output variables and unexpected output variables. Expected output is measured using the GDP of each province at 2000 constant prices. Undesirable output is measured using a pollutant emission index, which includes wastewater, exhaust gas, and solid waste. Descriptive statistics for input and output variables are shown in Table 1.

\section{Internet}

To measure the internet development level, researchers currently adopt single indicators such as internet penetration, number of internet users, and number of websites. However, a single index can only reflect part of the internet development and cannot comprehensively reflect the quality of internet development. To overcome this limitation, we construct an internet development index based on Han's [25] research.

We constructed a comprehensive evaluation index system from five individual indices: internet infrastructure, internet equipment resources, internet information resources, internet penetration rate, 
Table 1. Descriptive statistics of input and output variables.

\begin{tabular}{|c|c|c|c|c|c|}
\hline Variable & Unit & Mean & Std & Min & Max \\
\hline Labor force & $10^{4}$ people & 2585.06 & 1706.66 & 291.04 & 2016 \\
\hline Capital stock & $10^{8} \mathrm{CNY}$ & 31927.06 & 25967.92 & 2075.54 & 141675 \\
\hline Energy consumption & $10^{4}$ tons tce & 12759.63 & 8053.99 & 822.20 & 38899.30 \\
\hline Pollution emissions & - & 36582.81 & 27690.42 & 2794.74 & 123889 \\
\hline GDP & $10^{8} \mathrm{CNY}$ & 15998.61 & 14365.35 & 543.32 & 80854.90 \\
\hline
\end{tabular}

Table 2. Measurement index system for internet development level.

\begin{tabular}{|c|c|c|c|}
\hline Individual index & Secondary indices & Unit & Mean value \\
\hline \multirow{2}{*}{ Internet infrastructure } & Cable density & $\begin{array}{c}\text { Km/10,000 square } \\
\text { meters }\end{array}$ & 2002.07 \\
\hline \multirow{3}{*}{ Internet equipment resources } & Domain name per 10,000 people & Number/10000 & 311.72 \\
\cline { 2 - 4 } & Number of internet broadband access ports & Ten thousand & 2372.31 \\
\cline { 2 - 4 } & Proportion of IPv4 addresses & $\%$ & 141179.30 \\
\hline \multirow{3}{*}{ Internet information resources } & Total number of websites & Ten thousand & 47.33 \\
\cline { 2 - 4 } & Average number of bytes on a website & - & 53.89 \\
\hline \multirow{3}{*}{ Internet penetration rate } & Internet penetration & ten thousand people & 2433.31 \\
\cline { 2 - 4 } & Number of internet users & CNY & 57485.63 \\
\hline \multirow{2}{*}{ Internet development environment } & GDP per capita & CNY & 32440.37 \\
\cline { 2 - 4 } & Urban per capita disposable income & Ten thousand pieces & 102517.50 \\
\cline { 2 - 4 } & Express delivery volume & & \\
\hline
\end{tabular}

and internet development environment (Table 2). Considering the correlation between various indicators and the difference in their influence on the internet development level, we used principal component analysis to construct an internet comprehensive development index. The construction process is as follows:

It is assumed that there are $k$ indicators reflecting the internet development level with a time length of $T$, and the data set constitutes a matrix $X_{T \times k}, R_{k \times k}$ is the covariance matrix of $K$ index series. Then it calculates the eigenvalue $\lambda_{i}$ of $R_{k \times k}$ and the corresponding orthogonalized unit eigenvector $a_{i}$. Each principal component can be expressed as:

$$
F_{i}=a_{1 i} X_{i}+a_{2 i} X_{2}+\cdots a_{K i} X_{k} \quad i=1, \cdots, k(10)
$$

This study uses each principal component $\left(F_{1}, \ldots, F_{k}\right)$ to make a linear combination, and take the variance contribution rate $\beta$, of each principal component as the weight to construct the internet development index. The formula is as follows:

internet development index $=\beta_{1} F_{1}+\beta_{2} F_{2}+\cdots+\beta_{k} F_{k}$
All data passed Bartlett's spherical test and the Kaiser-Meyer-Olkin (KMO) test, indicating that they were suitable for principal component analysis. The cumulative variance contribution rate of the first $K$ principal components was $80 \%$ to determine the number of principal components. According to formula 11, we calculated the comprehensive score, i.e., the comprehensive development index of internet.

\section{Mediating Variables}

Based on previous theoretical analysis, we selected industrial structure upgrading (ISU) and technological innovation (TI) as mediating variables to test the indirect impact mechanisms of internet on regional green productivity. Technological innovation was represented by the number of patents, and industrial structure upgrading was measured by the proportion of high-end technology industrial output value in the GDP.

\section{Control Variables}

To obtain unbiased estimation results, a number of additional variables were also controlled. Urbanization rate (UR) was estimated by the proportion of the urban population to the total population. Trade openness (TO) 
Table 3. Descriptive statistics of variables.

\begin{tabular}{|c|c|c|c|c|c|c|}
\hline Variable & Definition & Mean & Std & Min & Max & Obs \\
\hline GML & Global Malmquist-Luenberger index & 1.095 & 0.121 & 0.866 & 1.523 & 330 \\
\hline Internet & Internet development index & 3.64 & 2.35 & 0.199 & 12.68 & 330 \\
\hline UR & The proportion of the urban population to the total population & 0.529 & 0.137 & 0.274 & 0.896 & 330 \\
\hline TO & The ratio of total import and export to the GDP & 0.319 & 0.383 & 0.009 & 1.721 & 330 \\
\hline IPP & The ratio of technology market transaction value to the GDP & 0.999 & 2.23 & 0.017 & 15.353 & 330 \\
\hline ES & The proportion of coal in total energy consumption & 0.957 & 0.381 & 0.122 & 2.028 & 330 \\
\hline ER & Per capita industrial sulfur dioxide emissions & 0.163 & 0.134 & 0.005 & 1.422 & 330 \\
\hline TI & The number of patents & 2.917 & 4.89 & 0.010 & 26.994 & 330 \\
\hline ISU & The proportion of high-end technology industrial output value in the GDP & 0.124 & 0.127 & 0.002 & 0.506 & 330 \\
\hline $\mathrm{RD}$ & The proportion of RD investment in the GDP & 0.143 & 0.011 & 0.020 & 0.060 & 330 \\
\hline
\end{tabular}

was measured by the ratio of total import and export to the GDP. Intellectual property protection (IPP) was expressed as the ratio of technology market transaction value to the GDP. The proportion of coal in total energy consumption was used to measure the energy structure (ES). Environmental regulations (ER) was measured by per capita industrial sulfur dioxide emissions. Research and development (RD) investment was measured by the proportion of RD investment in the GDP.

\section{Data Collection}

The sample interval for this study extended from 2006 to 2016. Given the lack of data from China's Hong Kong, Macao, and Taiwan regions and the Tibet Autonomous Region, we selected the remaining 30 provinces as samples for analysis. Pollutant emission data were collected from the China Environmental Statistics Yearbook. Internet index data were mainly derived from the statistical report of internet development in China. Patent data, RD investment data, and high-tech industry output value data were obtained from China's science and technology statistical yearbook. The energy consumption data were obtained from the China Energy Statistics Yearbook. Other data without special explanation are from the China Statistical Yearbook and provincial statistical yearbooks. Variables definition and descriptive statistics in this paper are shown in Table 3.

\section{Empirical Results and Discussion}

\section{Baseline Regression Analysis}

Based on the Hausman test results, a two-way fixed effects model was adopted to estimate parameters in this study. For comparative analysis, both random effect and fixed effect regression results are shown in Table 4. The estimated coefficient of internet variable on
GML was 0.051 and passed the significance threshold at the $1 \%$ level, indicating that internet development has significantly improved China's regional green productivity in general. This conclusion confirms the view that internet has a direct positive effect on regional green productivity, as proposed in Hypothesis 1 . It implies that the internet has reduced environmental pollution while promoting economic growth. The result is basically consistent with Vu's [21] research on the economic effect of internet. It is also similar to Danish's [9] study on the environmental impact of the internet. The wide application of the Internet in the field of production and consumption has contributed to improving the efficiency of resource utilization, saving energy consumption and reducing pollution emission.

Among the control variables, the impact of urbanization on green productivity was positive but not statistically significant. Trade openness had a significant negative impact on green productivity, confirming the existence of a pollution haven effect in China. In the race to the bottom, local governments have lowered environmental standards to attract investment from multinational companies in the interest of economic growth, resulting in more environmental pollution and resource consumption, which hampers the growth of green productivity. Intellectual property protection played a significant role in promoting green productivity, which is mainly realized through improved progress in green technology. Energy structure had a significant negative effect on green productivity, indicating that increased coal consumption reduces green productivity. There was no clear impact of environmental regulation on China's green productivity during the sample period.

To further explore regional differences in the role of internet in green productivity, we divided the provinces of China into three regions: eastern, central, and western. As shown in Table 5, internet had a significant positive effect on green productivity in the eastern and middle regions but not in the western region. Internet 
Table 4. Baseline regression results.

\begin{tabular}{|c|c|c|c|c|c|}
\hline Variable & Pooled OLS & Individual-fixed effects & Time-fixed effects & Two-way fixed effects & Random effects \\
\hline \multirow{2}{*}{ Internet } & $0.035 * * *$ & $0.026 * * *$ & $0.051 * * *$ & $0.051^{* * *}$ & $0.053 * * *$ \\
\hline & (13.14) & $(5.83)$ & $(4.31)$ & $(9.87)$ & $(11.53)$ \\
\hline \multirow{2}{*}{ UR } & $-0.411 * * *$ & $-0.484 * * *$ & 0.332 & 0.332 & $-0.10 * * *$ \\
\hline & $(-6.06)$ & $(-2.61)$ & $(0.99)$ & $(1.54)$ & $(-0.84)$ \\
\hline \multirow{2}{*}{ TO } & $0.094 * * *$ & $-0.092 * * *$ & $-0.131 * *$ & $-0.131 * * *$ & -0.103 \\
\hline & $(4.53)$ & $(-2.50)$ & $(-2.62)$ & $(-3.90)$ & $(-3.55)$ \\
\hline \multirow{2}{*}{ IPP } & $0.014 * * *$ & $0.021 * * *$ & $0.030 * * *$ & $0.03 * * *$ & $0.022 * * *$ \\
\hline & 5.33 & $(3.34)$ & $(4.30)$ & $(5.36)$ & $(5.42)$ \\
\hline \multirow{2}{*}{ ES } & $-0.070 * * *$ & $-0.082 * *$ & 0.096 & $-0.095 * * *$ & $-0.082 * * *$ \\
\hline & $(-4.49)$ & $(-2.20)$ & $(-1.28)$ & $(-2.90)$ & $(-3.36)$ \\
\hline \multirow{2}{*}{ ER } & $0.134 * * *$ & 0.068 & 0.53 & 0.053 & $0.071^{*}$ \\
\hline & $(3.21)$ & $(1.47)$ & $(1.15)$ & $(1.32)$ & $(1.87)$ \\
\hline \multirow{2}{*}{ Constant } & $1.184 * * *$ & $1.329 * * *$ & 0.669 & $0.921 * * *$ & $1.10 * * *$ \\
\hline & $(39.19)$ & $(15.68)$ & $(3.08)$ & $(8.96)$ & (19.29) \\
\hline Year & & & Y & $\mathrm{Y}$ & \\
\hline Province & & Y & & Y & \\
\hline Observations & 330 & 330 & 330 & 330 & 330 \\
\hline$R$-squared & 0.52 & 0.42 & 0.588 & 0.58 & 0.58 \\
\hline
\end{tabular}

Note: $* \mathrm{P}<0.05, * * \mathrm{P}<0.01, * * * \mathrm{P}<0.001$

may not have played a positive role in improving environmental performance and resource utilization efficiency in western China because its development remains at a low level in this region. This study is somewhat similar to that of Han and Zhu' [51] research. They found that broadband penetration has a significant effect on economic growth in the eastern and central regions, but not in the western regions in China.

\section{Panel Quantile Regression}

Traditional linear regression can only reflect the average effects of independent variables on dependent variables; it cannot capture the whole picture of the relationships between model variables. At the same time, the parameter estimation results of mean reversion are also susceptible to the influence of extreme values. Therefore, we used a panel quantile regression model to further investigate the relationship between internet and green productivity at different sub-points. Table 6 shows the marginal effect of internet on green productivity at four quantiles. The coefficient of internet gradually increased and was significant and positive at the $30 \%$ to $90 \%$ quantiles, indicating that the positive effect of internet gradually increased with improvements in green productivity. This may reflect better integration of internet with industry in regions with higher green productivity, causing it to have a greater positive impact on economic growth and the environment.

\section{Mechanisms by Which Internet Affects Green Productivity}

\section{Mediating Effect Analysis}

Table 7 presents the roles of two mediating variables between internet and green productivity: technological innovation and industrial structure upgrading. Columns 1-3 contain estimated results with technological innovation as the mediating variable, and columns 4-6 contain estimated results with industrial structure upgrading as the mediating variable. Column 2 shows that the influence coefficient of internet on technological innovation is significant and positive, indicating that internet has a positive impact on technological innovation. Likewise, the regression coefficient of technological innovation on green productivity in Column 3 is also significant and positive, indicating that internet can indirectly promote green productivity growth through its positive impact on technological innovation. Equations 3 and 4 can be used to get that the direct and indirect effects are 0.029 and 0.022 , respectively (Table 8). Indirect effects accounted for $43 \%$ of the total effect. 
Table 5. Regional differences in the influence of internet on green productivity.

\begin{tabular}{|c|c|c|c|}
\hline Variable & East & Middle & West \\
\hline \multirow{2}{*}{ Internet } & $0.619 * * *$ & $0.044 * *$ & 0.009 \\
\hline & $(5.64)$ & $(2.26)$ & $(1.00)$ \\
\hline \multirow{2}{*}{ UR } & 0.498 & -1.465 & $1.387 * * *$ \\
\hline & $(1.36)$ & $(-1.23)$ & $(4.43)$ \\
\hline \multirow{2}{*}{ TO } & $-0.135 * * *$ & $0.985 * * *$ & 0.051 \\
\hline & $(-2.68)$ & $(3.12)$ & $(1.02)$ \\
\hline \multirow{2}{*}{ IPP } & $0.047 * * *$ & $0.066^{* * *}$ & 0.0003 \\
\hline & $(6.06)$ & $(3.71)$ & $(0.03)$ \\
\hline \multirow{2}{*}{ ES } & $0.3143^{* *}$ & 0.017 & -0.024 \\
\hline & (1.03) & $(0.14)$ & $(-0.63)$ \\
\hline \multirow{2}{*}{ ER } & $-1.240 * * *$ & $0.884 * * *$ & 0.039 \\
\hline & $(-2.95)$ & $(3.57)$ & $(1.01)$ \\
\hline \multirow{2}{*}{ Constant } & $0.747 * * *$ & $1.262 * * *$ & $0.452 * * *$ \\
\hline & $(3.42)$ & $(3.19)$ & $(3.20)$ \\
\hline Year & Y & Y & Y \\
\hline Province & Y & Y & Y \\
\hline Observations & 330 & 330 & 330 \\
\hline$R$-squared & 0.850 & 0.686 & 0.348 \\
\hline
\end{tabular}

Note: $* \mathrm{P}<0.05, * * \mathrm{P}<0.01, * * * \mathrm{P}<0.001$

Columns 4-6 in Table 7 are estimated results with industrial structure upgrading as the mediating variable. The influence coefficient of internet on industrial structure upgrading was 0.667 and significant, and the influence coefficient of industrial upgrading on regional green productivity was 0.003 and significant, indicating that internet improves regional green productivity by promoting the positive mediation effect of industrial structure upgrading. The direct effect of internet on green productivity was 0.049 , and its indirect effect through industrial upgrading was 0.002 (Table 8).

Overall, the effect of internet was significant and positive after considering the effects of technological innovation and industrial structure upgrading, indicating that there was an incomplete mediation effect. In addition, the direct effect of internet on green productivity was greater than the indirect effect. The findings relative to the indirect effect confirm the proposal of Hypothesis 2 that internet has an indirect effect on regional green productivity.

\section{Nonlinear Effect Analysis}

\section{Threshold Effect Test}

Before performing panel threshold regression, it is necessary to determine whether there is a threshold
Table 6. Quantile analysis results for the impact of internet on green productivity.

\begin{tabular}{|c|c|c|c|c|}
\hline Variable & $\mathrm{Q} 1=(0.3)$ & $\mathrm{Q} 2=(0.5)$ & $\mathrm{Q} 3=(0.7)$ & $\mathrm{Q} 4=(0.9)$ \\
\hline \multirow{3}{*}{ Internet } & $0.023^{* * *}$ & $0.031^{* * *}$ & $0.0422^{* * *}$ & $0.052^{* * *}$ \\
\cline { 2 - 5 } & $(4.76)$ & $(7.00)$ & $(10.44)$ & $(20.15)$ \\
\hline \multirow{2}{*}{ UR } & $-0.273 * * *$ & $-0.307 * * *$ & $-0.301 * * *$ & $-0.330 * *$ \\
\cline { 2 - 5 } & $(-3.51)$ & $(-3.96)$ & $(-4.84)$ & $(-3.27)$ \\
\hline \multirow{2}{*}{ TO } & 0.055 & 0.039 & 0.012 & 0.003 \\
\cline { 2 - 5 } & $(1.90)$ & $(1.64)$ & $(0.55)$ & $(0.09)$ \\
\hline \multirow{2}{*}{ IPP } & $0.142 * * *$ & $0.017 * * *$ & $0.014 * * *$ & 0.01 \\
\cline { 2 - 5 } & $(2.91)$ & $(5.00)$ & $(5.48)$ & $(2.37)$ \\
\hline \multirow{2}{*}{ ES } & $-0.072 * *$ & $-0.063 * * *$ & $-0.055^{* * *}$ & $-0.057 * * *$ \\
\cline { 2 - 5 } & $(-4.24)$ & $(-4.31)$ & $(-2.79)$ & $(-2.00)$ \\
\hline \multirow{2}{*}{ ER } & 0.056 & 0.057 & 0.098 & $0.114 * * *$ \\
\cline { 2 - 5 } & $(1.06)$ & $(1.36)$ & $(1.26)$ & $(1.47)$ \\
\hline \multirow{2}{*}{ Constant } & $1.147 * * *$ & $1.166 * * *$ & $1.166 * * *$ & $1.197 * * *$ \\
\cline { 2 - 5 } & $(43.14)$ & $(31.92)$ & $(32.08)$ & $(25.60)$ \\
\hline
\end{tabular}

Note: $* \mathrm{P}<0.05, * * \mathrm{P}<0.01, * * * \mathrm{P}<0.001$

effect and the specific amount of threshold check. Based on the method of Hansen [48], we conducted a panel threshold existence test. Table 9 reports the F-statistics of five model threshold tests and the thresholds and confidence intervals obtained by bootstrap simulation. When internet was taken as a threshold variable, only a single threshold test was passed, and the threshold value was 6.141 . When $R \& D$ investment and industrial structure upgrading were taken as threshold variables, the impact of internet on regional green productivity passed the double threshold test. After the above analyses, we established the threshold weight of each threshold variable. The following section will analyze the regression results of the threshold regression model.

\section{Threshold Regression Results}

As shown in Table 10, when internet was used as the threshold variable, the coefficient was positive but did not pass the significance test when the development level of internet was lower than the threshold (6.141). However, when the development level of internet crossed the threshold (6.141), it significantly promoted green productivity growth. In the early stages of internet development, the role of internet in promoting economic development and reducing environmental pollution may not be obvious. But when the level of internet development reaches the critical threshold where network effects play a role, it effectively promotes economic growth and reduces the impact of resources and the environment. Based on the findings above, we can conclude that the positive effect of internet on green 
Table 7. Mediating effect analysis.

\begin{tabular}{|c|c|c|c|c|c|c|}
\hline & (1) & (2) & (3) & (4) & (5) & (6) \\
\hline & GML & TI & GML & GML & ISU & GML \\
\hline \multirow[t]{2}{*}{ Internet } & $0.051^{* * *}$ & $0.022 * * *$ & $0.029 * * *$ & $0.051^{* * *}$ & $0.677^{* *}$ & $0.049 * * *$ \\
\hline & (11.53) & (13.22) & $(4.75)$ & (11.53) & (2.74) & $(9.40)$ \\
\hline \multirow[t]{2}{*}{$\mathrm{TI}$} & & & $0.96^{* * *}$ & & & \\
\hline & & & (5.52) & & & \\
\hline \multirow[t]{2}{*}{ ISU } & & & & & & $0.003^{* * *}$ \\
\hline & & & & & & (2.83) \\
\hline \multirow[t]{2}{*}{ UR } & 0.332 & $0.199 * * *$ & $0.139 * * *$ & 0.332 & 0.156 & 0.278 \\
\hline & (1.54) & (2.87) & $(0.67)$ & (1.54) & $(1.51)$ & (3.55) \\
\hline \multirow[t]{2}{*}{ TO } & $-0.131 * * *$ & $-0.063 * * *$ & $-0.069 * *$ & $-0.131 * * *$ & $0.131 * * *$ & $-0.177 * * *$ \\
\hline & $(-3.90)$ & $(-5.83)$ & $(-2.07)$ & $(-3.90)$ & $(8.16)$ & $(-4.79)$ \\
\hline \multirow[t]{2}{*}{ IPP } & $0.03 * * *$ & 0.001 & $0.029 * * *$ & $0.03 * * *$ & $0.009^{* * *}$ & $0.026^{* * *}$ \\
\hline & (5.36) & $(0.72)$ & (5.39) & (5.36) & (3.36) & $(4.76)$ \\
\hline \multirow[t]{2}{*}{ ES } & $-0.095 * * *$ & -0.004 & $-0.091 * * *$ & $-0.095 * * *$ & $-0.046^{* * *}$ & $-0.080 * *$ \\
\hline & $(-2.90)$ & $(-0.40)$ & $(-2.92)$ & $(-2.90)$ & $(-2.90)$ & $(-2.41)$ \\
\hline \multirow[t]{2}{*}{ ER } & 0.053 & 0.013 & 0.040 & 0.053 & -0.009 & 0.056 \\
\hline & $(1.32)$ & $(1.06)$ & $(1.04)$ & $(1.32)$ & $(-0.49)$ & $(1.42)$ \\
\hline \multirow[t]{2}{*}{ Constant } & $0.921 * * *$ & $-0.083 * *$ & $1.003 * * *$ & $0.921 * * *$ & 0.023 & $0.914 * * *$ \\
\hline & $(8.96)$ & $(-2.54)$ & $(10.13)$ & $(8.96)$ & $(0.47)$ & $(8.99)$ \\
\hline Year & $\mathrm{Y}$ & $\mathrm{Y}$ & $\mathrm{Y}$ & $\mathrm{Y}$ & $\mathrm{Y}$ & $\mathrm{Y}$ \\
\hline Province & $\mathrm{Y}$ & $\mathrm{Y}$ & $\mathrm{Y}$ & $\mathrm{Y}$ & $\mathrm{Y}$ & $\mathrm{Y}$ \\
\hline Observations & 330 & 330 & 330 & 330 & 330 & 330 \\
\hline$R$-squared & & 0.683 & 0.627 & & 0.721 & 0.599 \\
\hline
\end{tabular}

Note: $* \mathrm{P}<0.05, * * \mathrm{P}<0.01, * * * \mathrm{P}<0.001$

productivity is non-linear; that is, there is a network effect. The results of this study are similar to Vu's [21] results from 207 world economies, in which the effect of internet popularization on economic growth demonstrated a significant network effect. They are also consistent with Guo and Luo's [52] research on the impact of internet on total factor productivity in China, which confirmed the existence of network effect.

Table 8. Summary of effects.

\begin{tabular}{|c|c|c|}
\hline & TI & ISU \\
\hline Total effect & 0.051 & 0.051 \\
\hline Direct effect & 0.029 & 0.049 \\
\hline Indirect effect & 0.022 & 0.002 \\
\hline Ratio of indirect to total effect (\%) & $43 \%$ & $4 \%$ \\
\hline
\end{tabular}

Internet had a negative impact on green productivity when RD was lower than the threshold value (1.22). When it crossed the second threshold, the coefficient was positive. When it crossed the third threshold, internet had a greater positive impact on green productivity. When RD is low, internet technology may still be under research and development, and it may be difficult for manufacturers to develop and apply internet technology on a large scale. Internet development not only has no positive impact on the economy but may also consume resources and have a negative impact on economic growth. However, when RD is high, internetrelated technologies become increasingly mature, and internet is popularized and applied across all of society, with positive effects on economic growth, energy conservation, and emission reduction.

When industrial structure upgrading was below the threshold value (0.074), internet had a significant negative impact on green productivity. However, when it crossed the second threshold, internet had 
Table 9. Threshold significance tests and threshold value estimation results

\begin{tabular}{|c|c|c|c|c|}
\hline Threshold variable & Hypothesis test & $P$ value & Threshold value & $95 \%$ confidence interval \\
\hline \multirow{2}{*}{ Internet } & Single threshold & 0.000 & 6.141 & {$[5.945,6.534]$} \\
\hline \multirow{3}{*}{ RD } & Single threshold & 0.000 & 1.96 & {$[1.799,1.993]$} \\
\cline { 2 - 5 } & Double threshold & 0.007 & 1.22 & {$[1.21,1.25]$} \\
\cline { 2 - 5 } & & & 1.96 & {$[1.88,1.993]$} \\
\hline \multirow{3}{*}{ ISU } & Single threshold & 0.000 & 21.820 & {$[19.549,25.274]$} \\
\cline { 2 - 5 } & Double threshold & 0.077 & 8.020 & {$[19.659,25.274]$} \\
\cline { 2 - 5 } & & & 21.820 & \\
\hline
\end{tabular}

Table 10. Threshold model regression results.

\begin{tabular}{|c|c|c|c|c|c|c|}
\hline Variable & (1) & & (2) & & (3) & \\
\hline Internet $\leq 6.141$ & 0.002 & 0.43 & & & & \\
\hline Internet $>6.141$ & $0.016^{* * *}$ & 3.48 & & & & \\
\hline $\mathrm{RD} \leq 1.22$ & & & -0.005 & -1.07 & & \\
\hline $1.22<\mathrm{RD} \leq 1.96$ & & & $0.011 * *$ & 2.52 & & \\
\hline $1.96<\mathrm{RD}$ & & & $0.029 * * *$ & 7.72 & & \\
\hline ISU $\leq 0.074$ & & & & & -0.006 & -1.12 \\
\hline $0.074<\mathrm{ISU} \leq 0.371$ & & & & & $0.015 * * *$ & 3.55 \\
\hline $0.371<$ ISU & & & & & $0.048 * * *$ & 9.99 \\
\hline UR & 0.169 & 0.82 & 0.122 & 0.73 & 0.147 & 0.87 \\
\hline $\mathrm{TO}$ & $-0.086^{* *}$ & -2.48 & -0.017 & -0.55 & 0.020 & 0.57 \\
\hline IPP & $0.019 * * *$ & 3.21 & $0.016 * * *$ & 3.01 & $0.011 * *$ & 2.00 \\
\hline ES & $-0.064 *$ & -1.82 & $-0.074 *$ & -2.31 & -0.025 & -0.77 \\
\hline ER & 0.059 & 1.35 & 0.052 & 1.35 & 0.059 & 1.51 \\
\hline Constant & $1.04 * * *$ & 11.13 & $1.04 * * *$ & 13.67 & $0.951 * * *$ & 11.77 \\
\hline Observations & 330 & 330 & 330 & 330 & 330 & 330 \\
\hline$R$-squared & 0.565 & & 0.593 & & 0.583 & \\
\hline
\end{tabular}

Note: $* \mathrm{P}<0.05, * * \mathrm{P}<0.01, * * * \mathrm{P}<0.001$

a significant positive impact on green productivity, and when the third threshold was crossed, internet had an even stronger positive impact. The effect of internet on green productivity therefore increased with continual improvements in industrial structure upgrading. It may be that as industrial structures are upgraded, various sectors generate higher demands for internet services, forcing internet to undergo technological innovation, promoting stronger effects on green productivity.

\section{Robustness and Endogeneity Tests}

To test the robustness of the results, we used the provincial internet penetration rate as an alternative internet development indicator to estimate results. The coefficients of the core explanatory variables and the control variables were consistent, suggesting that the main conclusions of this paper were robust and further confirming the initial research hypotheses. It is worth noting that when a single internet indicator was used to replace comprehensive indicators, the effect intensity of internet was significantly reduced. This reflects the fact that internet development is a comprehensive system, and the use of only a single index for research may lead to an underestimation of the spillover effect of internet.

Measurement errors, missing variables, and mutual causation may lead to endogeneity problems. To address potential endogeneity caused by measurement error, we adopted the GML index method to calculate dependent variables such as green productivity, and a comprehensive index method to estimate internet development level, thereby reducing 
Table 11. Robustness and endogeneity tests.

\begin{tabular}{|c|c|c|c|c|c|c|}
\hline & \multicolumn{2}{|c|}{ Robustness test } & \multicolumn{4}{c|}{ Endogeneity test } \\
\hline & Internet penetration & & IV_2SLS (t-1)) & & IV_2SLS(t-2) & \\
\hline Internet & $0.002 * * *$ & 2.92 & $0.079 * * *$ & 4.96 & $0.111^{* * *}$ & 5.56 \\
\hline UR & 0.081 & 0.55 & $-0.460^{* *}$ & -2.36 & $-0.915^{* * *}$ & -3.72 \\
\hline TO & $-0.111 * * *$ & -3.56 & -0.002 & -0.04 & $0.119^{* *}$ & 1.99 \\
\hline IPP & $0.022^{* * *}$ & 4.45 & $0.021^{* * *}$ & 3.11 & $0.022^{* * *}$ & 2.89 \\
\hline ES & $-0.118^{* * *}$ & -4.09 & $-0.098^{* *}$ & -2.47 & $-0.087 *$ & -1.95 \\
\hline ER & 0.024 & 0.52 & 0.052 & 1.14 & 0.057 & 1.27 \\
\hline Constant & $1.117 * * *$ & 16.23 & $1.407 * * *$ & 14.31 & $1.600^{* * *}$ & 13.35 \\
\hline Observations & 330 & & 330 & & 330 & \\
\hline$R$-squared & 0.355 & & 0.470 & & 0.472 & \\
\hline
\end{tabular}

Note: $* \mathrm{P}<0.05, * * \mathrm{P}<0.01, * * * \mathrm{P}<0.001$

the influence of data quality on the estimated results. At the same time, we also used authoritative data from the national bureau of statistics as the data source. To address the issue of missing variables, we adopted the method of adding control variables to control them.

Endogenous problems caused by mutual cause and effect were an important challenge to be solved in this study: Internet promotes the improvement of green productivity, which in turn may promote the development of internet. To analyze the main source of causality, we used one-period lag internet as the core explanatory variable for regression analysis. As shown in the Column 4 of Table 11, the regression results are basically consistent with the previous conclusions. For the sake of caution, we also used two-period lag internet as the instrumental variable for the current internet to perform regression. As shown in Column 6 of Table 11, the regression results of the instrumental variable method were consistent with the previous basic regression results.

\section{Research Conclusions and Policy Recommendations}

\section{Research Conclusions}

We used China's provincial panel data from 2006 to 2017 to construct a comprehensive internet development index and empirically test the impact of internet on green productivity. The main conclusions were as follows:

First, internet significantly promoted green productivity in China. Second, there was significant spatial heterogeneity in the impact of internet on green productivity, with positive impacts in the eastern and central regions of China, but none in the western region. Third, internet could indirectly improve regional green productivity by promoting technological innovation and industrial upgrading, but the indirect effect was weaker than the direct effect.

Finally, there was a significant threshold effect of internet development on green productivity in China. When internet development was low, internet had a significant negative effect on green productivity; when it exceeded a critical value, it had a significant positive effect, and this effect was significantly greater than that at a low level of internet development. Furthermore, the effect of internet in promoting green productivity was non-linear. With an increase in the scale of internet use, the impact also increased; that is, there was a network effect. At the same time, the mediators such as technological innovation and industrial upgrading also positively strengthened the network effect of internet.

\section{Policy Recommendations}

Based on the research conclusions above, we put forward a number of policy recommendations. The research shows that internet has a network effect on green productivity, and it can significantly promote green growth when internet develops to a certain level. In view of the development level of China's internet and the future trend of economic digital transformation, the government should increase investment to promote the construction of new generation mobile communication network infrastructure including $5 \mathrm{G}$ and quantum communication, further improve the development level of internet, and stimulate the network effect of internet. The impact of internet on western China is not significant, which reflects the problem of digital divide in China [53]. It is necessary to increase internet infrastructure construction and policy support in the inland provinces of China, improve the internet development level in central and western regions, and thereby narrowing digital and green productivity gaps between regions. 
Second, the government should promote the deep integration of internet with industry and accelerate the construction of a green, low-carbon industrial system by means of network information. It is necessary to make full use of internet to promote new processes and technologies for energy conservation and emission reduction, promote clean production in pollutionintensive industries, and ultimately realize industrial structure transformation and upgrades. In addition, it should accelerate the integrated development of the internet, transportation and energy, construct a green, smart and shared transportation system [54], and further reduce energy consumption and pollution emissions in the transport sector [55].

Finally, the internet indirectly affects green growth by promoting technological innovation and upgrading industrial structure. Therefore, we need to pay attention to the intermediary role of indirect factors such as technological innovation and industrial upgrading, and give full play to the spillover effect of the internet in green growth. Enterprises should further improve their innovation ability, increase their efficiency of resource utilization, and reduce the negative impact of production activities on the ecological environment with the help of internet platform.

\section{Outlook}

This paper attempts to integrate the internet and green productivity into a framework, and analyze the internal mechanism of the internet's influence on green productivity by using mediation model and panel threshold model. The contents and methods of this study provide a valuable reference for the exploration of related fields in the future. However, we mainly focus on the internet's contribution to green growth through technological innovation and industrial structure upgrading, which is the innovation point of this paper as well as the research limitation. In fact, the impact of the internet is extensive. It not only has an impact on technological innovation and industrial upgrading, but also may have an important impact on human capital, energy consumption, environmental regulation, management technology, consumer behavior and other factors, thus affecting green productivity. Theoretically, these factors may become the mediating variables between the internet and green productivity. Therefore, there is more room for explore in this area in the future.

\section{Acknowledgements}

This research was funded by Humanity and Social Science Youth foundation of Ministry of Education of China [Grant No. 20YJCZH068], the Research Project of Philosophy and Social Sciences in Colleges and universities in Shanxi Province [Grant No. 2019W093], the Planning of Philosophy and Social Sciences in Shanxi Province [Grant No. 2019B149], the Soft
Science Research Program of Shanxi Province [Grant No. 2018041003-4] [Grant No. 2019041035-2], and Youth Foundation of Shanxi University of Finance and Economics [Grant No. QN-2019012].

\section{Conflict of Interest}

The authors declare no conflict of interest.

\section{References}

1. LI D., WU R. A Dynamic Analysis of Green Productivity Growth for Cities in Xinjiang. Sustainability, 10 (2), 515, 2018.

2. DONG F., ZHANG S., LONG R., ZHANG X., SUN Z. Determinants of haze pollution: An analysis from the perspective of spatiotemporal heterogeneity. Journal of Cleaner Production, 222, 768, 2019.

3. DONG F., LI J., WANG Y., ZHANG X., ZHANG S., ZHANG S. Drivers of the decoupling indicator between the economic growth and energy-related $\mathrm{CO} 2$ in China: A revisit from the perspectives of decomposition and spatiotemporal heterogeneity. Science of The Total Environment, 685, 631, 2019.

4. DONG F., YU B., PAN Y. Examining the synergistic effect of $\mathrm{CO}_{2}$ emissions on PM2.5 emissions reduction: Evidence from China. Journal of Cleaner Production, 223, 759, 2019.

5. China Environmental Planning Institute. China's economic and ecological GDP accounting development report 2018. Beijing: China Environment press, 2018.

6. MA L., LONG H., CHEN K., TU S., ZHANG Y., LIAO L. Green growth efficiency of Chinese cities and its spatiotemporal pattern. Resources, Conservation and Recycling, 146, 441, 2019.

7. SUN Y., DING W., YANG Z., YANG G., DU J. Measuring China's regional inclusive green growth. Sci Total Environ, 713, 136367, 2020

8. ASONGU S.A., ODHIAMBO N.M. Foreign direct investment, information technology and economic growth dynamics in Sub-Saharan Africa. Telecommunications Policy, 44 (1), 2020.

9. DANISH. Effects of information and communication technology and real income on $\mathrm{CO}_{2}$ emissions: The experience of countries along Belt and Road. Telematics and Informatics, 45, 2019.

10. China Internet Information Center. Statistical report on Internet development in 2018. Beijing, 2019.

11. GUO L., IING Q.Y., TSENG M.L. The interaction effects of environmental regulation and technological innovation on regional green growth performance. Journal of Cleaner Production, 162, 894, 2017.

12. YAN Z., ZOU B., DU K., LI K. Do renewable energy technology innovations promote China's green productivity growth? Fresh evidence from partially linear functionalcoefficient models. Energy Economics, 90, 104842, 2020.

13. YUE S., YANG Y., HU Y. Does Foreign Direct Investment Affect Green Growth? Evidence from China's Experience. Sustainability, 8 (2), 2016.

14. YOO S.-H., KWAK S. Information technology and economic development in Korea: A causality study. International Journal of Technology Management, 27, 2004. 
15. MEIJERS H. Does the internet generate economic growth, international trade, or both? International Economics \& Economic Policy, 11 (1-2), 137, 2014.

16. Chu S.Y. Internet, Economic Growth and Recession. Modern Economy, 4 (3A), 209, 2013.

17. HARRIS R.G. The internet as a GPT: factor market implications. General purpose technologies and economic growth, 145, 1998.

18. CHOI C., HOON Y.M. The effect of the Internet on economic growth: Evidence from cross-country panel data. Economics Letters, 105 (1), 39, 2009.

19. CZERNICH N., FALACK O., KRETSCHMER T., WOESSMANN L. Broadband Infrastructure and Economic Growth. Economic Journal, 121 (552), 505, 2011.

20. MAURSETH P.B. The effect of the Internet on economic growth: Counter-evidence from cross-country panel data. Economics Letters, 172, 74, 2018.

21. VU K.M. The internet-growth link: An examination of studies with conflicting results and new evidence on the network effect. Telecommunications Policy, 43 (5), 474, 2019.

22. CONLEY T.G., UDRY C.R. Learning About a New Technology: Pineapple in Ghana. American Economic Review, 100 (1), 2005.

23. GLAVAS C., MATHEWS S. How international entrepreneurship characteristics influence Internet capabilities for the international business processes of the firm. International Business Review, 23 (1), 228, 2014.

24. PAUNOV C., ROLLO V. Overcoming Obstacles: The Internet's Contribution to Firm Development. The World Bank Economic Review, 29 (suppl 1), S192, 2015.

25. XIANFENG H., WENFEI S., BOXIN L. Can the Internet become a new momentum to improve the efficiency of regional innovation in China. China Industrial Economics(In Chinese), 7, 119, 2019.

26. VEMURI V.K., SIDDIQI S. Impact of Commercialization of the Internet on International Trade: A Panel Study Using the Extended Gravity Model. International Trade Journal, 23 (4), 458, 2009.

27. CLARKE G.R.G., WALLSTEN S.J. Has the Internet Increased Trade? Developed and Developing Country Evidence. Economic Inquiry, 44 (3), 465, 2010.

28. BLOOM N., KRETSCHMER T., REENEN J.V. Are family-friendly workplace practices a valuable firm resource? Strategic Management Journal, 32 (4), 343, 2011.

29. CASTELLACCI F., VINAS-BARDOLET C. Internet use and job satisfaction. Computers in Human Behavior, 90, 141, 2019.

30. BEARD T.R., FORD G.S., SABA R.P., Seals R.A. Internet use and job search. Telecommunications Policy, 36 (4), 260, 2012.

31. STEVENSON B. Studies of Labor Market Intermediation: The Internet and Job Search. University of Chicago Press, 2009.

32. ERDMANN L., HILTY L.M. Scenario Analysis: Exploring the Macroeconomic Impacts of Information and Communication Technologies on Greenhouse Gas Emissions. Journal of Industrial Ecology, 14 (5), 826, 2010.

33. ISHIDA H. The effect of ICT development on economic growth and energy consumption in Japan. Telematics and Informatics, 32 (1), 79, 2015.

34. CHAVANNE X., SCHINELLA S., MARQUET D., FRANGI J.P., LE MASSON S. Electricity consumption of telecommunication equipment to achieve a telemeeting. Applied Energy, 137, 273, 2015.

35. HASEEB A., XIA E., SAUD S., AHMAD A., KHURSHID $H$. Does information and communication technologies improve environmental quality in the era of globalization? An empirical analysis. Environmental ence and Pollution Research, 26, 8594, 2019.

36. OZCAN B., APERGIS N. The impact of internet use on air pollution: Evidence from emerging countries. Environmental ence \& Pollution Research, 25, 4174, 2018.

37. SALAHUDDIN M., ALAM K., Ozturk I. The effects of Internet usage and economic growth on $\mathrm{CO}_{2}$ emissions in OECD countries: A panel investigation. Renewable and Sustainable Energy Reviews, 62, 1226, 2016.

38. LEE J.W., BRAHMASRENE T. ICT, $\mathrm{CO}_{2}$ Emissions and Economic Growth: Evidence from a Panel of ASEAN. Global Economic Review, 43, 93, 2014.

39. AÑÓN H.D., GHOLAMI R., SHIRAZI F. ICT and environmental sustainability: A global perspective. Telematics and Informatics, 34 (4), 85, 2017.

40. DEHGHAN SHABANI Z., SHAHNAZI R. Energy consumption, carbon dioxide emissions, information and communications technology, and gross domestic product in Iranian economic sectors: A panel causality analysis. Energy, 169, 1064, 2019.

41. HILTY L.M., ARNFALK P., ERDMANN L., GOODMAN J., LEHMANN M., WÄGER P.A. The relevance of information and communication technologies for environmental sustainability - A prospective simulation study. Environmental Modelling \& Software, 21 (11), $1618,2006$.

42. FUNK J.L. IT and sustainability: New strategies for reducing carbon emissions and resource usage in transportation. Telecommunications Policy, 39 (10), 861, 2015.

43. TAKASE K., MUROTA Y. The impact of IT investment on energy: Japan and US comparison in 2010. Energy Policy, 32 (11), 1291, 2004.

44. MOYER J.D., HUGHES B.B. ICTs: Do they contribute to increased carbon emissions? Technological Forecasting and Social Change, 79 (5), 919, 2012.

45. LARS-HENDRIK R., LEONARD W. Telecommunications Infrastructure and Economic Development: A Simultaneous Approach. The American economic review, 91 (4), 909, 2001.

46. ROLLER L.-H., WAVERMAN L. Telecommunications Infrastructure and Economic Development: A Simultaneous Approach. American Economic Review, 91 (4), 909, 2001.

47. GRUBER H., HÄTÖNEN J., KOUTROUMPIS P. Broadband access in the EU: An assessment of future economic benefits. Telecommunications Policy, 38 (11), 1046, 2014.

48. HANSEN B.E. Threshold effects in non-dynamic panels: Estimation, testing, and inference. Journal of Econometrics, 93 (2), 345, 1999.

49. CHUNG Y., FARE R. Productivity and Undesirable Outputs: A Directional Distance Function Approach. Microeconomics, 51 (3), 229, 1997.

50. OH D.H. A global Malmquist-Luenberger productivity index. Journal of Productivity Analysis, 34 (3), 183, 2010.

51. HAN B.G., ZHU P.F. An empirical analysis of the impact of broadband on China's economic growth. Statistical research, 31 (010), 49, 2014 [In Chinese]. 
52. GUO J.D., LUO P.L. Does the Internet promote China's total factor productivity. Management World, 10, 34, 2016 [In Chinese].

53. SONG Z.Y., WANG C., BERGMANN L. China's prefectural digital divide: Spatial analysis and multivariate determinants of ICT diffusion - ScienceDirect. International Journal of Information Management, 52. 102072, 2020.

54. DONG F., LIU Y. Policy evolution and effect evaluation of new-energy vehicle industry in China. Resources Policy, 67, 101655, 2020.
55. MATHIESEN B.V., LUND H., CONNOLLY D., WENZEL H., ØSTERGAARD P.A., MÖLLER B., NIELSEN S., RIDJAN I., KARNØE P., SPERLING K., HVELPLUND F.K. Smart Energy Systems for coherent 100\% renewable energy and transport solutions. Applied Energy, 145, 139, 2015. 